\title{
Concerted Actions of Octopamine and Dopamine Receptors Drive Olfactory Learning
}

\author{
John Martin Sabandal,^ Paul Rafael Sabandal,* Young-Cho Kim, and Kyung-An Han \\ Department of Biological Sciences, University of Texas at El Paso, El Paso, Texas 79968
}

\begin{abstract}
Aminergic signaling modulates associative learning and memory. Substantial advance has been made in Drosophila on the dopamine receptors and circuits mediating olfactory learning; however, our knowledge of other aminergic modulation lags behind. To address this knowledge gap, we investigated the role of octopamine in olfactory conditioning. Here, we report that octopamine activity through the $\beta$-adrenergic-like receptor Oct $\beta 1 \mathrm{R}$ drives aversive and appetitive learning: Oct $\beta 1 \mathrm{R}$ in the mushroom body $\alpha \beta$ neurons processes aversive learning, whereas Oct $\beta 1 R$ in the projection neurons mediates appetitive learning. Our genetic interaction and imaging studies pinpoint cAMP signaling as a key downstream effector for Oct $\beta 1 \mathrm{R}$ function. The rutabaga-adenylyl cyclase synthesizes cAMP in a $\mathrm{Ca}^{2+} /$ calmodulin-dependent manner, serving as a coincidence detector for associative learning and likely representing a downstream target for Oct $\beta 1 R$. Supporting this notion, the double heterozygous rutabaga $/+;$ oct $\beta 1 r /+$ flies perform poorly in both aversive and appetitive conditioning, while individual heterozygous rutabaga/ + and oct $\beta 1 r /+$ flies behave like the wild-type control. Consistently, the mushroom body and projection neurons in the oct $\beta 1 r$ brain exhibit blunted responses to octopamine when cAMP levels are monitored through the cAMP sensor. We previously demonstrated the pivotal functions of the $\mathrm{D}_{1}$ receptor $\mathrm{dDA} 1$ in aversive and appetitive learning, and the $\alpha 1$ adrenergic-like receptor OAMB in appetitive learning. As expected, oct $\beta 1 r$ genetically interacts with $d u m b$ (dDA1 mutant) in aversive and appetitive learning, but it interacts with oamb only in appetitive learning. This study uncovers the indispensable contributions of dopamine and octopamine signaling to aversive and appetitive learning. All experiments were performed on mixed sex unless otherwise noted.
\end{abstract}

Key words: cAMP; dopamine; learning; memory; mushroom body; octopamine

Significance Statement

Animals make flexible behavioral choices that are constantly shaped by experience. This plasticity is vital for animals to appropriately respond to the cues predicting benefit or harm. In Drosophila, dopamine is known to mediate both reward-based and punishmentbased learning while octopamine function is important only for reward. Here, we demonstrate that the octopamine-Oct $\beta$ 1R-cAMP pathway processes both aversive and appetitive learning in distinct neural sites of the olfactory circuit. Furthermore, we show that the octopamine-Oct $\beta 1 \mathrm{R}$ and dopamine-dDA1 signals together drive both aversive and appetitive learning, whereas the octopamine$\mathrm{Oct} \beta 1 \mathrm{R}$ and octopamine-OAMB pathways jointly facilitate appetitive, but not aversive, learning. This study identifies the cognate actions of octopamine and dopamine signaling as a key neural mechanism for associative learning.

Received July 19, 2019; revised Mar. 12, 2020; accepted Mar. 29, 2020.

Author contributions: J.M.S., P.R.S., Y.-C.K., and K.-A.H. designed research; J.M.S., P.R.S., and Y.-C.K. performed research; J.M.S., P.R.S., Y.-C.K., and K.-A.H. analyzed data; K.-A.H. wrote the paper.

*J.M.S. and P.R.S. contributed equally to this work.

The authors declare no competing financial interests.

This work was supported by US Department of Agriculture Grant NIFA2010-65 105-20 625, Brain \& Behavior Research Foundation NARSAD grants, National Institutes of Health (NIH) National Institute of Mental Health Grant R21-MH-109953, and National Institute on Minority Health and Health Disparities Neuromodulation Disorders Cluster Grant 2G12MD007592. We thank the Bloomington Stock Center; the Exelixis Collection, and Drs. David Anderson (California Institute of Technology, Pasadena, CA), Josh Dubnau (Stony Brook University School of Medicine, Stony Brook, NY), Ann-Shyn Chiang (National Tsing Hua University, Hsinchu, Taiwan), Andreas Thum (University of Leipzig, Leipzig, Germany) and Scott Waddell (University of Oxford, Oxford, UK) for sharing fly lines; the Cytometry, Screening and Imaging Core at the Border Biomedical Research Center for help on confocal microscopy; the NIH-funded MARC program (Grant 5T34-GM-008048) for supporting J.M.S.; and a Keelung Hong Fellowship for supporting P.R.S. We also thank past and current laboratory members for their discussion and support.

J.M. Sabandal's present address: Department of Neuroscience, The Scripps Research Institute Florida, Jupiter, FL 33410.

\section{Introduction}

Experiential learning facilitates animals to promptly respond to pleasant or noxious cues for approach or avoidance, respectively, for fitness and survival. In Drosophila melanogaster, olfactory classical conditioning is widely used to assess the capacity of the organism to learn and remember the odor associated with electric shock punishment (aversive) or sugar reward (appetitive) for delineating the neural, cellular, and molecular mechanisms. Olfactory learning and memory require modulatory actions of

Y.-C. Kim's present address: Department of Neurology, University of lowa Hospitals and Clinics, lowa City, IA 52242.

Correspondence should be addressed to Kyung-An Han at khan@utep.edu.

https://doi.org/10.1523/JNEUROSCI.1756-19.2020

Copyright $\odot 2020$ the authors 
multiple aminergic systems including dopamine (DA), octopamine (OA; an invertebrate counterpart of norepinephrine), and serotonin (5-HT; Schwaerzel et al., 2003; Kim et al., 2007a,b; Johnson et al., 2011; Sitaraman et al., 2012; Aso et al., 2014a,b; Iliadi et al., 2017). The fundamental question of how diverse aminergic signals converge within the learning and memory pathways remains incompletely resolved. The actions of modulatory neurotransmitters like DA and OA are initiated on their binding to one or more of their respective receptors in overlapping or parallel neural circuits, conveying additive, synergistic, or antagonistic interactions via intracellular effectors to acquire, store, or retrieve information. OA and 5-HT, for example in aversive conditioning, exert additive effects on intermediate memory through their actions on distinct mushroom body (MB) substructures (Wu et al., 2013), whereas DA via DAMB in the MB has an antagonistic effect by promoting forgetting (Berry et al., 2012). All three monoamines are important for olfactory learning as well; however, the nature of interactions and circuits that DA, $\mathrm{OA}$, and 5-HT shape the ability of the fly to acquire aversive and appetitive memories are unknown.

The best characterized of all three monoamines in olfactory conditioning is DA (Guven-Ozkan and Davis, 2014; Aso et al., 2014a,b; Cognigni et al., 2018). Ectopic activation of discrete PPL1 or PAM DA neurons projecting to the MB substitutes the aversive or appetitive unconditioned stimulus (US), respectively, when paired with the conditioned stimulus (CS; Claridge-Chang et al., 2009; Liu et al., 2012). The DA signals for aversive and appetitive learning require the $D_{1}$ receptor $d D A 1$ in the $M B$, while ongoing DA activity after learning through the $\mathrm{D}_{5}$ receptor DAMB regulates forgetting (Kim et al., 2007a; Berry et al., 2012; Qin et al., 2012). The dual functions of DA for memory acquisition and forgetting are executed through the following divergent intracellular effectors: dDA1 engages G $\alpha$ s/cAMP signaling, whereas DAMB recruits $\mathrm{G} \alpha \mathrm{q} / \mathrm{Ca}^{2+}$ signaling (Himmelreich et al., 2017). These findings posit DA as a major contributor to aversive as well as appetitive learning and memory.

$\mathrm{OA}$ is a major neuromodulator for appetitive learning. The $t \beta h$ mutant lacking tyramine $\beta$ hydroxylase $(\mathrm{T} \beta \mathrm{H})$, a rate-limiting enzyme for OA biosynthesis, is defective in the acquisition of appetitive memory in olfactory conditioning (Schwaerzel et al., 2003; Kim et al., 2007b). The function of OA in appetitive learning engages the $\alpha 1$-like $\mathrm{OA}$ receptor $\mathrm{OAMB}$ in the $\mathrm{MB}$ $\alpha \beta \gamma$ neurons (Han et al., 1998; Kim et al., 2013). The role of OA in aversive olfactory learning, however, is yet unsettled. Two studies report contrasting findings on the $t \beta h$ mutant: Schwaerzel et al. (2003) demonstrate normal performance, whereas Iliadi et al. (2017) report poor performance in aversive conditioning. It is worth noting that the discrepancy is not due to the nature of mutation in $t \beta h$, the mutant genetic background, or conditioning parameters. Intermediate-term aversive memory, nonetheless, is shown to require the OA signal through the $\beta$-like OA receptor $\operatorname{Oct} \beta 2 \mathrm{R}$ in the $\mathrm{MB} \alpha^{\prime} \beta^{\prime}$ neurons (Wu et al., 2013). In operant courtship conditioning, a different type of aversive conditioning, OAMB in the MB $\alpha \beta$ neurons, mediates the OA signal for short-term memory of courtship suppression (Zhou et al., 2012). While these reports illustrate the functions of $\mathrm{OA}$ in aversive memory, the key issue that is yet unresolved but important regarding mechanism is whether the OA signal is involved only in appetitive learning or both appetitive and aversive learning. In this report, we address this issue and further delineate the neural sites and intracellular effectors critical for olfactory conditioning.

\section{Materials and Methods}

Drosophila strains and culture. The wild-type strain used in this study is Canton-S, and the mutant defective in Oct $\beta 1 \mathrm{R}$ is the piggyBac transgenic line oct $\beta 1 r^{f 02819}$ generated by the Gene Disruption Project (Thibault et al., 2004). The oct $\beta 1 r^{f 02819}$ in the $w^{1118}$ genetic background was obtained from the Bloomington Drosophila Stock Center (BDSC; stock \#18589) and placed in the Canton-S genetic background by backcrossing with Cantonized $w^{1118}$ for six generations and then replacing the $\mathrm{X}$ chromosome containing $w^{1118}$ with the Canton-S X chromosome with the normal $w$ gene (hereafter called oct $\beta$ 1r). We previously described oamb, oct $\beta 2 r$, dumb, and elav-GAL4,Gal80 ${ }^{t s}$ (Lee et al., 2003; Kim et al., 2007a; Lim et al., 2014). The Deficiency (Df) lines $D f(3 R)$ Exel6191 (stock \#7670) and Df(3R)BSC685 (stock \#26537), tdc2-GAL4 (stock \#9313), elav-GAL4 (stock \#8765), OK107-GAL4 (stock \#854), c739-GAL4 (stock \#7362), c305a-GAL4 (stock \#30829), and UAS-Epac1camps (stock \#25407 and \#25408) were obtained from the BDSC; T $\beta h$ $R N A i$ (v51667) were obtained from the Vienna Drosophila Resource Center; $p B D P-G A L 4$ was provided by David Anderson (California Institute of Technology, Pasadena, CA); NP1131-GAL4 and APL-GAL4 (VT43924-GAL4 recombined with UAS-GAL4 on the third chromosome) were provided by Josh Dubnau (Stony Brook University School of Medicine, Stony Brook, NY) and Ann-Shyn Chiang (National Tsing Hua University, Hsinchu City, Taiwan); and NP225-GAL4 was provided by Andreas Thum (University of Konstanz, Konstanz, Germany).

The open reading frame of $\operatorname{Oct} \beta 1 \mathrm{R}$ (Maqueira et al., 2005) was cloned under UAS in the gateway vector pTW (Akbari et al., 2009), and transgenic $U A S-O c t \beta 1 R$ lines were generated by germ line transformation in $w^{1118}$ embryos as previously described (Lim et al., 2014). Germline-transformed lines were outcrossed with Cantonized $w^{1118}$ for at least six generations, and the transgenes were placed in the oct $\beta 1 r$ genetic background for rescue experiments. All fly lines were maintained on standard cornmeal/agar/yeast medium. Flies were collected under $\mathrm{CO}_{2}$ within $2 \mathrm{~d}$ after eclosion and 65-70 flies representing a group were housed together in a food vial at $25^{\circ} \mathrm{C}$ with $\sim 50 \%$ relative humidity under the $12 \mathrm{~h}$ light/dark cycle before testing. Unless otherwise stated, the 4- to 7-d-old flies of mixed sex were used for all experiments. For the temporal control of GAL4 activity, the control and experimental flies carrying elav-GAL4,GAL80 $0^{t s}$ were reared at $30^{\circ} \mathrm{C}$ for the induction of GAL4 activity or at $20^{\circ} \mathrm{C}$ for no induction. For developmental induction, flies were reared at $30^{\circ} \mathrm{C}$ until a mid-pupal stage and then maintained at $20^{\circ} \mathrm{C}$ before conditioning. For adulthood induction, flies were reared at $20^{\circ} \mathrm{C}$ throughout development and for $1 \mathrm{~d}$ after eclosion, and then maintained at $30^{\circ} \mathrm{C}$ for $3 \mathrm{~d}$ before conditioning. For the genetic interaction experiments, the virgin females of oct $\beta 1 r$ or Canton- $S$ were crossed with rutabaga (rut), dumb, or oamb males. In the case of rut, which is on the $\mathrm{X}$ chromosome, only the female progeny of oct $\beta 1 \mathrm{r}$ or Canton-S crossed with rut were used for conditioning.

RNA analysis. The transcript levels of Canton-S and oct $\beta 1 r$ flies were analyzed as previously described (Lim et al., 2014). Three independent sets of 50 heads per genotype were homogenized in $10 \mu \mathrm{l}$ of RLT lysis buffer (Qiagen) with the KONTES Micro Tissue Grinder (Thermo Fisher Scientific), which was then applied to the QIAshredder Spin Column (Qiagen). Total RNA was extracted using the RNeasy Protect Mini Kit (Qiagen), and then cDNA was generated using the Invitrogen SuperScript III First-Strand Synthesis System (for RT-PCR). Quantitative PCR was conducted using the iQ SYBR Green Supermix Kit (Bio-Rad) and the StepOnePlus Real-Time PCR Detection System (Applied Biosystems) per the manufacturer instructions. The 100, 200, and $400 \mathrm{ng}$ of cDNA samples were run in triplicate, and the reactions were performed with the primer sets for oct $\beta 1 r$, the experimental gene, and $r p 49$, a ribosomal protein gene as a control, to quantify relative expression levels. The primer sets were designed to span at least one intron and checked for specificity using the BLAST (FlyBase Consortium, 2003) against the Drosophila genome. The PCR primers 
used in this study are as follows: for oct $\beta 1$, forward-TGT GCA GCC ACT GGA CTA TC, reverse-TAT GGC GTA TGC CTT GTT CA; for rp49, forward-TAC ACGG CCC AAG ATC GTG AA, reverse-GTT CGA TCC GTA ACC GAT GT.

Behavioral tests. All experiments were performed blindly (i.e., an experimenter does not know the genotype of the fly lines when conducting all experiments). The protocol described by Kim et al. (2007a,b) were used for aversive and appetitive conditioning with slight modifications. Training and tests were conducted under dim red light and 50-60\% relative humidity. Odorants used for conditioning were $2 \%$ ethyl acetate (EA; catalog \#319902-500, Sigma-Aldrich) and 2.2\% isoamyl acetate (IAA; catalog \#112674-500, Sigma-Aldrich). For appetitive conditioning, flies were starved for $18-20 \mathrm{~h}$ in the vials containing double-layered, water-soaked Kimwipes before training. A group of 65-70 flies were exposed to the first odor $\left(\mathrm{CS}^{+}\right)$paired with 12 pulses of $90 \mathrm{~V}$ electric shock (US) for aversive conditioning or $2 \mathrm{~m}$ sucrose (US) for appetitive conditioning for $1 \mathrm{~min}$ followed by $30 \mathrm{~s}$ of rest (interstimulus interval). After exposure to the second odor $\left(\mathrm{CS}^{-}\right)$without electric shock or sucrose for $1 \mathrm{~min}$, flies were tested immediately $(3 \mathrm{~min}), 1 \mathrm{~h}$, or $3 \mathrm{~h}$ after training. To measure the capacity of flies to learn and remember, the flies were gently transferred to a T-maze and tested for $2 \mathrm{~min}$ to assess their avoidance or preference of the $\mathrm{CS}^{+}$odor. A second group of flies was simultaneously trained with the odors presented in a reversed order to account for any possible odor bias in conditioning. For the short program single-training trial (1T) in aversive conditioning (Beck et al., 2000), flies were exposed to $\mathrm{CS}^{+}$odors for $10 \mathrm{~s}$ with a single pulse of 90 $\mathrm{V}$ electric shock followed by $30 \mathrm{~s}$ rest and then $\mathrm{CS}^{-}$odors for $10 \mathrm{~s}$ before tests. For the two-training trial $(2 \mathrm{~T})$, flies received another $1 \mathrm{~T}$ training program with $15 \mathrm{~min}$ intertraining interval (ITI). The performance index (PI) was calculated by subtracting the percentage of flies that made an incorrect choice from the percentage of flies that made a correct choice. The average PI of the two groups of flies conditioned with counterbalanced odors was used as one data point. For 1 and $3 \mathrm{~h}$ memory tests, trained flies were gently transferred back into their respective vials (food-containing vials for electric shock-conditioned flies or vials with water-soaked Kimwipes for sugar-conditioned flies) and maintained at room temperature before tests.

Control behaviors were examined as previously reported (Kim et al., 2007a, 2013) and include olfactory acuity, shock avoidance, and sugar preference without conditioning. Briefly, flies were placed in a T-maze and allowed to choose (odor vs air for olfactory acuity; 90 or $30 \mathrm{~V}$ vs no shock for shock avoidance; 2 or $0.2 \mathrm{M}$ sucrose vs water for sugar preference). An average PI of the counterbalanced set as noted above was calculated and reported as one data point.

cAMP imaging. The 4- to 7-d-old flies expressing the cAMP sensor Epacl-camps in the $\mathrm{MB}$ or projection neurons (PNs) in the wild-type or oct $\beta$ 1r genetic background were used for imaging. A fly brain was dissected within $3 \mathrm{~min}$ in the ice-cold hemolymph-like saline HL3 $(70 \mathrm{~mm}$ $\mathrm{NaCl}, 5 \mathrm{~mm} \mathrm{KCl}$, CaCl2 $1.5 \mathrm{~mm}, 20 \mathrm{~mm} \mathrm{MgCl} 2,10 \mathrm{~mm} \mathrm{NaHCO}_{3}, 5 \mathrm{~mm}$ trehalose, $115 \mathrm{~mm}$ sucrose, and $5 \mathrm{~mm}$ HEPES, pH 7.1) and placed on the microscope glass containing either HL3 (baseline or vehicle control) or HL3 with $100 \mu \mathrm{M}$ OA (treated), which was then covered with a coverslip. To create space between a microscope glass and a coverslip so as not to compress the brain, two layers of the scotch tape (3M) were placed on a microscope glass. The cAMP sensor Epacl-camps was excited at $440 \mathrm{~nm}$, and emission was detected at $480 \mathrm{~nm}$ for CFP and $540 \mathrm{~nm}$ for YFP (yellow fluorescent protein). Images were collected using the $20 \times$ objective in the LSM700 confocal microscope (Zeiss) at every micrometer with the $512 \times 512$ pixel resolution. Each brain was used only once for imaging, thus different brains were used for imaging baseline and OA treatments. For quantification, images in grayscale were used to measure fluorescence intensity per pixel in each optical section using ImageJ software (NIH). Fluorescence intensity per pixel was calculated by [Integrated density total $/$ Area $\left._{\text {total }}\right]$ per region of interest (ROI). We defined ROI in the major brain structures, including MB and PN. The non-ROI was defined in the anterior inferior medial protocerebrum (AIMPR) where the Epac1-camps was not induced. The fluorescence intensity for each CFP or YFP was calculated by [Integrated density/ Area $]_{\text {ROI }}-[\text { Integrated density/Area }]_{\text {non-ROI. }}$ The cAMP response was determined by calculating the inverse FRET ratio, which is $\left|\Delta R / R_{0}\right|$, where $R=$ CFP/YFP and $\Delta R=R_{\text {treated }}-R_{\text {nontreated was used for data }}$ presentation (Shafer et al., 2008; Tomchik and Davis, 2009). To determine the timeline of cAMP responses, the changes in Epac1-camps FRET were measured at several time points (i.e., 1, 3, 5, 10, or $30 \mathrm{~min}$ ) after OA or HL3 (control) treatment. For representative images of CFP and YFP emission in a fire scale, see Figures $4, A$ and $B$, and $5 C$, which exemplify relative cAMP levels.

Experimental design and statistical analyses. The 4- to 7-d-old flies of mixed sex were used for all experiments, with the exception of the genetic interaction experiment involving rut. As noted above, rut is on the $\mathrm{X}$ chromosome; thus, only female rut heterozygotes and female rut and $o c t \beta 1 r$ double heterozygotes were used. All behavioral experiments were performed blindly to the experimenter, and the control and experimental groups were tested in the same session in a randomized order. Multiple independent sets of flies obtained from different crosses and cultures were used for behavioral analyses. Statistical analyses were performed using the JMP (SAS) and Minitab 16 (Minitab). The raw data were analyzed using the Anderson-Darling goodness-of-fit or ShapiroWilk normality test for distribution and the Levene's test for equality of variances, and are reported as the mean \pm SEM. The normally distributed data were analyzed by a two-tailed Student's $t$ test for two groups or ANOVA followed by post hoc Tukey's multiple-comparison or Dunnett's tests for three or more groups. The non-normally distributed data were analyzed by Kruskal-Wallis and post hoc Mann-Whitney tests. Significant difference among the groups under comparison was determined using an $\alpha$ level of 0.05 in all analyses. All raw data files are available on request.

\section{Results}

\section{Oct $\beta 1 R$ is essential for aversive learning}

To clarify whether OA is involved in aversive learning, we used the RNA interference (RNAi) approach to reduce expression of the OA biosynthetic enzyme $\mathrm{T} \beta \mathrm{H}$. The $\mathrm{T} \beta \mathrm{H}$ knock-down flies were then examined in olfactory conditioning to assess their avoidance of the odor associated with electric shock. The GAL4 drivers expressed in a majority of OA neurons ( $t d c 2-G A L 4)$ and a pair of the tdc2-GAL4-negative anterior paired lateral (APL; APL-GAL4) OA neurons (Busch et al., 2009; Wu et al., 2013) were used for $\mathrm{T} \beta \mathrm{H}$ RNAi. Compared with the control $p B D P$ GAL4 (promoterless GAL4)/UAS- $t \beta h-R N A i$ flies, both $t d c 2$ GAL4/UAS-t $\beta h-R N A i$ and APL-GAL4/UAS-t $\beta h-R N A i$ flies performed poorly when tested right after training (ANOVA: $F_{(2,27)}=31.4, p<0.0001$; Fig. $\left.1 A\right)$. To clarify whether developmental or adulthood $\mathrm{T} \beta \mathrm{H}$ knockdown $(\mathrm{KD})$ is responsible for poor performance, we used elav-GAL4,GAL80 ${ }^{\text {ts }}$ (Kim et al., 2007a) to induce $\mathrm{T} \beta \mathrm{H}$ knockdown only during development, only during adulthood, or throughout development and adulthood. The flies with developmental $\mathrm{T} \beta \mathrm{H}$ knockdown showed normal performance in olfactory conditioning ( $t$ test: $t=$ $-0.12, p=0.9074$; Fig. $1 B$, developmental KD) similar to the flies without knockdown ( $t$ test: $t=-0.11, p=0.9168$; Fig. $1 B$, no KD). The flies with adulthood $\mathrm{T} \beta \mathrm{H}$ knockdown, however, displayed poor performance ( $t$ test: $t=-5.55, p<0.0001$; Fig. $1 B$, adulthood $\mathrm{KD}$ ) similar to the flies with constant knockdown ( $t$ test: $t=t$ test 5.7, $p<0.0001$; Fig. $1 B$, development and adulthood $\mathrm{KD}$ ). These results together indicate that $\mathrm{OA}$ is important for aversive olfactory conditioning and that multiple OA neurons are involved in the process.

Next, we investigated which OA receptor is important. The $\alpha 1$-like OAMB receptor is not crucial for aversive learning (Kim et al., 2013); thus, we focused on the $\beta$-like OA receptors $\operatorname{Oct} \beta 1 \mathrm{R}$ and $\operatorname{Oct} \beta 2 \mathrm{R}$. The oct $\beta$ 1r allele contains a piggyBac transposon in the second intron of the oct $\beta 1$ r gene with a splicing acceptor in the transposon in the right orientation to 
A

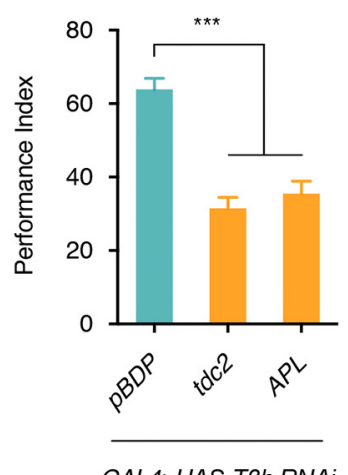

C

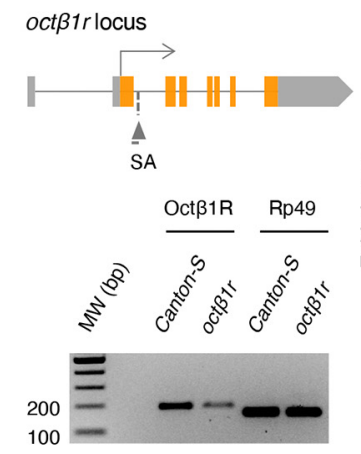

E

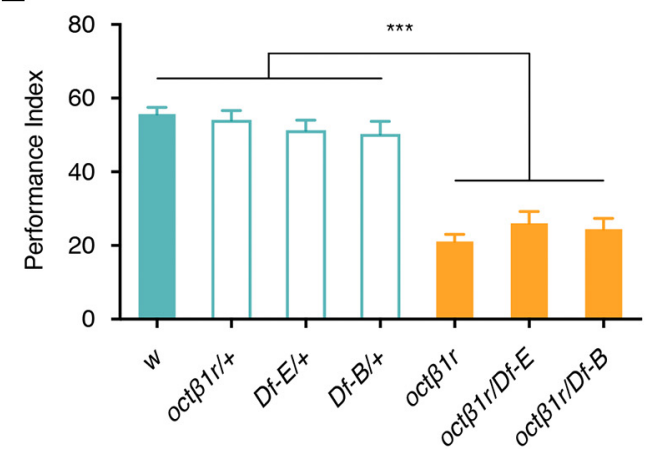

B

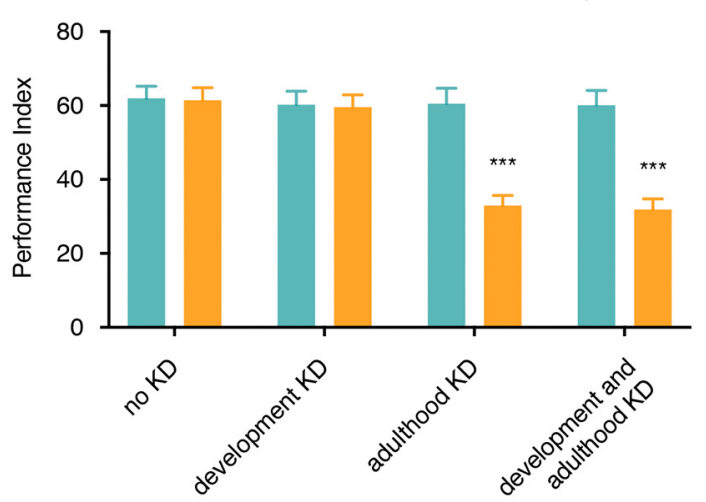

D

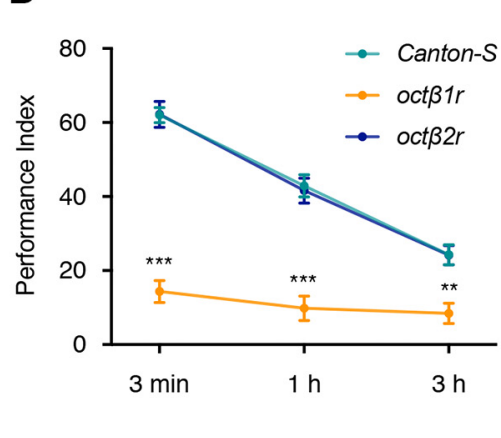

0.0011 ; Fig. $1 C$ ), indicating that $o c t \beta 1 r$ is a hypomorphic allele. We have previously shown that the oct $\beta 2 r$ mutant is a null allele for $\operatorname{Oct} \beta 2 \mathrm{R}$ (Lim et al., 2014). When tested immediately ( $3 \mathrm{~min}), 1$ or 3 $\mathrm{h}$ after electric-shock olfactory conditioning, the oct $\beta 2 r$ flies showed comparable performance and memory decay to the wild-type Canton-S, whereas the oct $\beta$ 1r flies displayed substantially poor performance right after training and subsequent time points (two-way ANOVA: $F_{(8,45)}=50.64, p<0.0001$; genotype effect: $F=118.4, p<0.0001$; time effect: $F=64.5, p<0.0001$; interaction effect: $F=9.8, p=0.0001$; Fig. $1 D$ ). These data suggest that aversive olfactory learning requires $\operatorname{Oct} \beta 1 \mathrm{R}$ but not $\operatorname{Oct} \beta 2 \mathrm{R}$.

To ascertain the phenotype of oct $\beta$ 1r to the oct $\beta 1 r$ locus, we tested the oct $\beta 1 r$ transheterozygotes over the $D f$ lines $D f(3 R)$ Exel6191 and $D f(3 R)$ BSC685 containing complete deletion of the oct $\beta$ 1r gene. The heterozygotes oct $\beta 1 r /+, D f(3 R)$ Exel6191/+, and $D f$ (3R)BSC685/+ had learning scores comparable to that of Canton-S; however, the transheterozygotes oct $\beta \mathrm{lr} /$ $D f(3 R)$ Exel6191 and oct $\beta 1 r / D f(3 R)$ BSC685 performed poorly like the oct $\beta 1 r$ homozygotes (ANOVA: $F_{(6,35)}$ $=33.39, p<0.0001$; Fig. $1 E$ ). This substantiates that the loss of oct $\beta$ 1r function rather than background genetic loci accounts for the learning phenotype. Two submaximal training trials (2T) with $15 \mathrm{~min}$ rest (ITI) in the short program of olfactory conditioning are known to improve the performance of the learning mutant rut (Beck et al., 2000). As in the regular electric shock conditioning, the oct $\beta 1 r$ flies displayed impaired performance compared with Canton-S in the 1T short program (Fig. $1 F$; two-tailed $t$ test: $t_{(22)}=-11.69$, $p<0.0001)$. The $2 \mathrm{~T}$ training with 15 min ITI, however, improved performance in the oct $\beta 1 r$ flies (Fig. $1 F$; twotailed $t$ test on $1 \mathrm{~T}$ vs $2 \mathrm{~T}: t_{(22)}=6.47$, $p<0.0001)$ similar to rut, further supporting the role of $\mathrm{Oct} \beta 1 \mathrm{R}$ in aversive olfactory learning. We next asked whether the learning phenotype could be due to abnormal sensory modalities. When tested with two different odor concentrations or shock intensities, Canton-S and oct $\beta 1 r$ flies showed comparable olfactory acuity and shock avoidance (Table 1). Together, the

intercept splicing of oct $\beta 1 r$ transcripts and generate a truncated protein (Fig. 1C). Quantitative RT-PCR analysis on the mRNA sequence spanning the exons 4 and 5 showed a reduced level of Oct $\beta 1 \mathrm{R}$ mRNA in oct $\beta$ 1r flies (one-sample $t$ test: $t=-29.533, p=$ results support that the function of $\operatorname{Oct} \beta 1 \mathrm{R}$ is needed to acquire aversive memory of olfactory information associated with electric shock. 
Table 1. Sensory modality tests including olfactory acuity, shock avoidance and sugar preference

\begin{tabular}{lllrl}
\hline & & Canton-S & \multicolumn{1}{l}{ oct $\beta$ 1r } & $p$ Value \\
\hline Olfactory acuity & 2\% EA & $63.69 \pm 2.54$ & $66.93 \pm 3.18$ & 0.45 \\
& $0.2 \%$ EA & $11.26 \pm 2.88$ & $13.89 \pm 4.42$ & 0.63 \\
& $2.2 \%$ IAA & $62.87 \pm 2.31$ & $67.29 \pm 3.73$ & 0.34 \\
& $0.22 \%$ IAA & $11.83 \pm 3.67$ & $12.6 \pm 2.92$ & 0.87 \\
Shock avoidance & $90 \mathrm{~V}$ & $65.04 \pm 5.23$ & $61.92 \pm 4.69$ & 0.67 \\
& $30 \mathrm{~V}$ & $36.48 \pm 3.89$ & $31.67 \pm 3.43$ & 0.38 \\
Sugar preference & 2 m sucrose & $63.00 \pm 1.91$ & $56.15 \pm 3.96$ & 0.16 \\
& 0.2 m sucrose & $43.07 \pm 2.96$ & $37.81 \pm 4.60$ & 0.36 \\
\hline
\end{tabular}

Canton-S and oct $\beta 1 r$ flies exhibited similar avoidance of the CS odors or the US electric shock as well as comparable preference to the US sugar, all of which were tested at two different doses $(n=6)$. Data are the mean \pm SEM, unless otherwise indicated.

\section{The site of the function of Oct $\beta 1 \mathrm{R}$ for aversive memory} formation is the $\mathrm{MB} \alpha \beta$ neurons

The genomic enhancer-driven reporter expression and singlecell RNA-sequencing studies report $\operatorname{Oct} \beta 1 \mathrm{R}$ expression in many neural structures including the PN and the MB (Pfeiffer et al., 2008; Li et al., 2017; Davie et al., 2018). To identify the functional site of $\operatorname{Oct} \beta 1 \mathrm{R}$, we performed rescue experiments using the GAL4/UAS system (Brand and Perrimon, 1993). We targeted the transgenic Oct $\beta 1 \mathrm{R}$ expression in the oct $\beta$ 1r mutant background pan-neuronally or in the second-order neurons (PN carrying olfactory information from the antennal lobe to $\mathrm{MB}$ ) or third-order neurons (MB) for the olfactory pathway, both of which are key neural structures for olfactory learning and memory (Guven-Ozkan and Davis, 2014). Pan-neuronal Oct $\beta 1 \mathrm{R}$ expression (elav-GAL4) fully reinstated the learning performance of oct $\beta$ 1r (ANOVA: $F_{(8,45)}=42.21, p<0.0001$; Fig. $2 A$ ). When targeted in a subset of neural structures, Oct $\beta 1 \mathrm{R}$ in all $\mathrm{MB}$ neurons (OK107-GAL4), but not in the PN neurons (NP225-GAL4), led to full rescue of the oct $\beta 1 r$ learning phenotype (Fig. 2A). The MB has three distinct substructures, namely $\alpha \beta, \alpha^{\prime} \beta^{\prime}$, and $\gamma$ neurons (Crittenden et al., 1998; Aso et al., 2014a), and they are engaged in distinct functions (Guven-Ozkan and Davis, 2014; Cognigni et al., 2018). The cell type-level transcriptome analysis indicates that $\operatorname{Oct} \beta 1 \mathrm{R}$ is abundant in all MB substructures (Shih et al., 2019). To narrow down the functional site within the MB, we used the substructure-specific GAL4 drivers along with the MB247-GAL4 expressed in $\alpha \beta$ and $\gamma$ for rescue experiments (Fig. $2 A$ ). The oct $\beta 1 r$ flies with reinstated $\operatorname{Oct} \beta 1 \mathrm{R}$ expression in the $\alpha \beta$ neurons (MB247-GAL4 and $c 739-G A L 4$ ) exhibited Canton-S-like performance (Fig. $2 A$ ), indicating full rescue. The $\operatorname{Oct} \beta 1 \mathrm{R}$ re-expression in other MB substructures, namely $\alpha^{\prime} \beta^{\prime}$ (c305a-GAL4) or $\gamma$ (NP1131-GAL4), had no effect (Fig. 2A). These results pinpoint the $\mathrm{MB} \alpha \beta$ neurons as the major functional substrate where $\operatorname{Oct} \beta 1 \mathrm{R}$ processes aversive learning.

Multiple lines of evidence show persistent Oct $\beta 1 \mathrm{R}$ expression from late embryonic to adult stages (Chintapalli et al., 2007; Graveley et al., 2011; Brown et al., 2014). To assess whether the phenotype of the oct $\beta 1 r$ is attributable to developmental or physiological anomaly, we restored $\operatorname{Oct} \beta 1 \mathrm{R}$ expression in the oct $\beta$ 1r mutant either during development or adulthood using the TARGET system (McGuire et al., 2003; Kim et al., 2007a, 2013). For induction of $\operatorname{Oct} \beta 1 \mathrm{R}$ expression, the $\operatorname{oct} \beta 1 \mathrm{r}$ flies carrying elaGal80 $0^{t s} / U A S-O c t \beta 1 R$ were reared at $30^{\circ} \mathrm{C}$ either during development or at the adulthood while the uninduced controls were kept at $20^{\circ} \mathrm{C}$ throughout development and adulthood (Fig. $2 B$ ). Oct $\beta 1 \mathrm{R}$ induced at the adult stage rescued the impaired learning phenotype of oct $\beta 1 r$ in aversive conditioning (ANOVA: $F_{(3,48)}=50.64, p<0.0001$; Fig. $2 B$ ), whereas induction only during development failed to do so (ANOVA: $F_{(3,44)}=43.64, p<0.0001$ ). These data indicate that the function of $\operatorname{Oct} \beta 1 \mathrm{R}$ in aversive learning is physiological as opposed to developmental.

\section{OA-DA interplay and intracellular signaling crucial for aversive learning}

Our earlier studies (Kim et al., 2007a, 2013) demonstrate that aversive learning requires the $\mathrm{MB} \mathrm{DA}$ receptor $\mathrm{dDA} 1$ but not the $M B O A$ receptor OAMB. Since the $M B$ is a functional site for $\operatorname{Oct} \beta 1 \mathrm{R}$ as well, we asked whether $\operatorname{Oct} \beta 1 \mathrm{R}$ and $\mathrm{dDA} 1$ act in collaboration for aversive learning by using a genetic interaction approach. When subjected to electric shock conditioning, all heterozygous receptor mutants showed normal learning, indicating the recessive nature of oct $\beta 1 r$ and $d u m b$ in this process. The oct $\beta 1 \mathrm{r} /$ dumb transheterozygotes, on the contrary, displayed significantly impaired performance (ANOVA: $F_{(5,36)}=13.62$, $p<0.0001$; Fig. $3 A$ ). This was not due to a simple combination of two heterozygous mutations since the oct $\beta$ 1r/oamb transheterozygotes showed normal learning. These data suggest that $\mathrm{dDA} 1$ and $\operatorname{Oct} \beta 1 \mathrm{R}$ have parallel functions to process aversive learning.

Like mammalian $\beta$-adrenergic receptors, $\operatorname{Oct} \beta 1 \mathrm{R}$ stimulates an increase in the intracellular cAMP level when studied in heterologous cells in vitro (Maqueira et al., 2005). The cAMP signaling pathway is an integral cellular mechanism for olfactory learning in flies (Guven-Ozkan and Davis, 2014). We conducted ex vivo imaging to visualize and quantify the changes in cAMP levels in the MB lobes of Canton-S and oct $\beta 1 r$. For the task, we used the pan-MB OK107-GAL4 to drive the cAMP sensor Epac1-camps, where an increase in cAMP causes a decrease in FRET between CFP and YFP (Nikolaev et al., 2004). We first determined the timeline of the cAMP response in the wild-type brain expressing Epac1-camps in the MB on $100 \mu \mathrm{M}$ OA or HL3 (control) treatment. The maximal increase in cAMP levels was evident within $1 \mathrm{~min}$ after $\mathrm{OA}$ treatment and sustained at least for $5 \mathrm{~min}$ (Fig. $4 \mathrm{~A}$ ); thus, we measured the cAMP response at 3 min after $\mathrm{OA}$ treatment in subsequent experiments. Compared with the control, the OA-induced cAMP response was substantially dampened across all $\mathrm{MB}$ subregions examined $\left(\alpha 3 / \alpha^{\prime} 3\right.$, $\alpha 2 / \alpha^{\prime} 2, \alpha 1 / \alpha^{\prime} 1 / \gamma 2, \beta 1 / 2$, and $\gamma 3-5$ ), except for $\beta^{\prime} 1 / 2$ and $\gamma 1 /$ heel (Fig. $4 B, C$ ). To clarify whether cAMP serves as a major downstream effector of $\operatorname{Oct} \beta 1 \mathrm{R}$ for olfactory learning, we examined the genetic interaction of oct $\beta 1 r$ and rut defective in the adenylyl cyclase (AC) that converts ATP to cAMP. Similar to oct $\beta 1 \mathrm{r} /+$, the rut heterozygotes $(\mathrm{rut} /+)$ showed normal performance but the rut/+;;oct $\beta 1 r /+$ double heterozygotes exhibited poor learning (Fig. $3 B$ ). These observations corroborate that OA signaling through $\operatorname{Oct} \beta 1 \mathrm{R}$ recruits $\mathrm{cAMP}$ to promote aversive learning.

\section{Oct $\beta 1 \mathrm{R}$ in the PN plays a major role in appetitive learning} $\mathrm{OA}$ is a major transmitter for appetitive conditioning (Schwaerzel et al., 2003; Kim et al., 2007b) and it's activity through $\alpha 1$-like $\mathrm{OAMB}$ in the $\mathrm{MB}$ is indispensable for appetitive memory formation (Kim et al., 2013). We asked whether $\beta$-like OA receptors are also important for appetitive learning. The Canton-S, oct $\beta 1 r$, and oct $\beta 2 r$ flies were conditioned with 2 m sucrose as US and the same odorants were used for aversive conditioning as CS. Canton-S and oct $\beta 2 r$ showed comparable performance when tested immediately, $1 \mathrm{~h}$, and $3 \mathrm{~h}$ after training; however, oct $\beta 1 \mathrm{r}$ displayed poor performance at all time points examined (two-way ANOVA: $F_{(11,60)}=$ 22.29, $p<0.0001$; genotype effect: $F=25.26, p<0.0001$; time effect: $F=58.82, p<0.0001$; interaction effect: $F=3.03, p=0.0118$; Fig. 
A

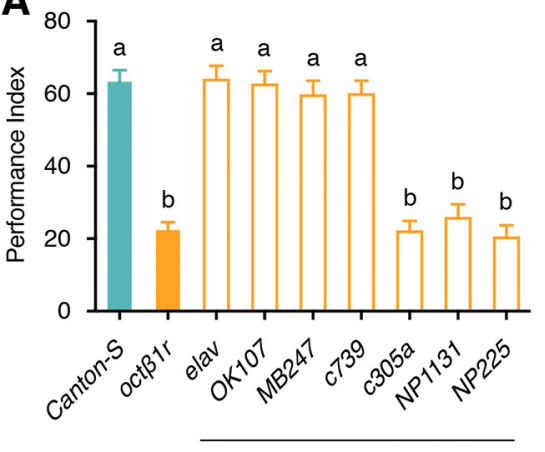

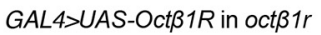

B

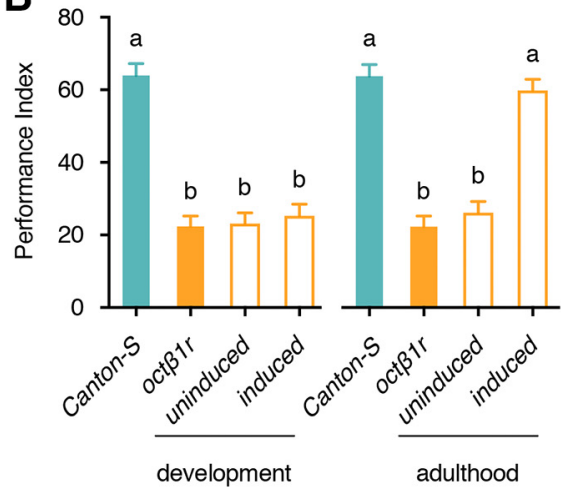

Figure 2. $0 \mathrm{ct} \beta 1 \mathrm{R}$ in the $\mathrm{MB} \alpha \beta$ neurons promotes acquisition of aversive memory. $\boldsymbol{A}$, Restored $0 \mathrm{ct} \beta 1 \mathrm{R}$ (UAS-Oct $\beta 1 R$ ) in all (elav-GAL4), pan-MB (OK107-GAL4), MB $\alpha \beta \gamma$ (MB247-GAL4), or MB $\alpha \beta$ (C739-GAL4) neurons rescued the learning defect of $\operatorname{oct} \beta \operatorname{1r}(p<0.0001, n=6)$. In contrast, the flies with $0 \mathrm{ct} \beta 1 \mathrm{R}$ re-expression in other MB neurons (MB $\gamma$, NP1131-GAL4; or MB $\alpha^{\prime} \beta^{\prime}$, c305a-GAL4) or the PN (NP225-GAL4) performed poorly similar to oct $\beta$ 1r mutants ( $p>0.05, n=6$ ). B, Normal aversive learning was reinstated in $0 c t \beta 1 \mathrm{r}$ mutants when $0 \mathrm{ct} \beta 1 \mathrm{R}$ was restored during adulthood (induced, temperature shift to $30^{\circ} \mathrm{C}$; uninduced, no temperature shift; $\left.p<0.0001, n=13\right)$, but not during development $(p>0.05, n=12)$. In this and other figures, letters on the bars denote either a significant difference among groups (different letters, i.e., "a" and " $b$ ") or no difference (same letters).

A

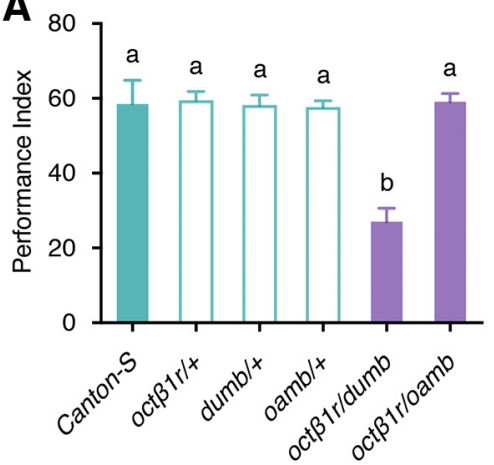

B

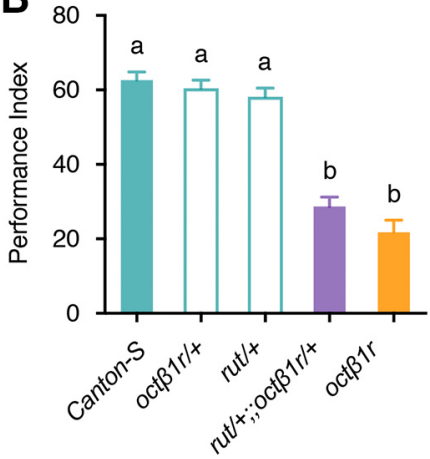

Figure 3. Interaction between $0 \mathrm{ct} \beta 1 \mathrm{R}$ and $\mathrm{dDA} 1$ concertedly drives aversive learning via CAMP. $\boldsymbol{A}$, The flies with the transheterozygous mutations in oct $\beta 1 \mathrm{r}$ and dumb (a mutant allele for dDA1) showed impaired learning (oct $\beta 1 r / d u m b ; p<0.0001$, $n=7$ ), but the oct $\beta 1 \mathrm{r}$ and oamb transheterozygotes (oct $\beta$ 1r/oamb) were comparable to either (anton-S control or the heterozygotes oct $\beta 1 \mathrm{r} /+$, dumb/+, and oamb/+ $(p>0.05, n=7)$. $\boldsymbol{B}$, The rut $/+; 0$ oct $\beta 1 \mathrm{r} /+$ double heterozygotes displayed impaired acquisition similar to oct $\beta$ 1r mutants $(p>0.05, n=8-9)$.

$5 A$ ). The impaired performance was not due to anomalous sugar perception (Table 1) or genetic background since the transheterozygotes oct $\beta$ 1r/Df(3R)Exel6191 and oct $\beta$ 1r/Df(3R)BSC685 also performed poorly like the oct $\beta 1 r$ mutant (data not shown). These results illustrate the crucial role of $\operatorname{Oct} \beta 1 \mathrm{R}$ for acquisition of appetitive memory as well. The impaired appetitive learning phenotype of oct $\beta 1 r$ was fully rescued when $\operatorname{Oct} \beta 1 \mathrm{R}$ was reinstated in all neurons (elav-GAL4) or the PN (NP225-GAL4) in the oct $\beta 1 r$ background (ANOVA: $F_{(6,77)}=31.01, p<0.0001$; Fig. $5 B$ ). Interestingly, the learning defect of oct $\beta 1 r$ was slightly improved when $\operatorname{Oct} \beta 1 \mathrm{R}$ was restored in the $\mathrm{MB} \alpha \beta, \alpha^{\prime} \beta^{\prime}$, or $\gamma$ neurons (Fig. $5 B$ ). These data suggest that $\operatorname{Oct} \beta 1 \mathrm{R}$ has redundant functions in multiple neural sites for appetitive learning with quantitatively different contributions, but its major functional site is the PN. Consistently, the OA-induced cAMP levels were significantly dampened in the PN dendrites at the $\mathrm{AL}$ and axons at the $\mathrm{MB}$ calyx area (Fig. $5 C, D$; dendrites: $t_{(22)}=-8.52, p<0.0001$; axons: $t_{(22)}=-13.64, p<0.0001$, two-tailed $t$ test).

To elucidate the relative contributions of $\operatorname{Oct} \beta 1 \mathrm{R}$ and $\mathrm{OAMB}$ to appetitive learning, we examined genetic interaction. Unlike the individual oct $\beta 1 \mathrm{r} /+$ and $o a m b /+$ heterozygotes that showed normal appetitive learning, the oct $\beta 1 \mathrm{r} / \mathrm{oamb}$ transheterozygote showed drastically diminished learning, which is comparable to that of the homozygous oct $\beta 1 r$ flies (ANOVA: $F_{(8,56)}=68.91, p<0.0001$; Fig. $\left.5 E\right)$. The $\mathrm{DA}$ receptor $\mathrm{dDA} 1$ plays a significant role in appetitive memory acquisition (Kim et al., 2007a); thus, we were curious whether $\operatorname{Oct} \beta 1 \mathrm{R}$ and $\mathrm{dDA} 1$ work together for appetitive learning. Similar to the oct $\beta 1 r$ and oamb genetic interaction, the oct $\beta 1 r / d u m b$ transheterozygote exhibited poor learning (Fig. 5E). These findings indicate that the concerted actions of $\operatorname{Oct} \beta 1 \mathrm{R}, \mathrm{OAMB}$, and $\mathrm{dDA} 1$ mediate appetitive learning.

\section{Discussion}

Historically, OA is known to mediate reward-based but not punishmentbased learning in Drosophila and other invertebrates including honeybees, crickets, and crabs (Farooqui et al., 2003; Schwaerzel et al., 2003; Kaczer and Maldonado, 2009; Mizunami and Matsumoto, 2017). This selective role of OA was first demonstrated by Schwaerzel et al. (2003) based on the observation that $t \beta h$ mutants are defective in appetitive learning, but not aversive learning. Recently, Iliadi et al. (2017) challenged this notion and showed that $t \beta h$ mutants are impaired in aversive learning. Both studies examined the same mutant allele and used the same conditioning parameters including CS odorants and US electric shock intensities; thus, the discrepancy in their findings remains puzzling. In this report, by adopting an RNAi approach, we provide the independent evidence that substantiates the finding of Iliadi et al. (2017) and further demonstrate that more than one type of OA neuron processes aversive learning through $\operatorname{Oct} \beta 1 \mathrm{R}$ in the $\mathrm{MB} \alpha \beta$ neurons.

OA neurons have widespread projections in the brain and are classified into 28 types based on their projection patterns, as follows: 27 types positive for tdc2-GAL4 and 1 type [i.e., anterior paired lateral (APL; APL-GAL4) neurons] negative for tdc2GAL4 (Busch et al., 2009; Wu et al., 2013). Our data indicate that both tdc2-GAL4 and APL OA neurons are important for aversive learning. Notably, the $\mathrm{MB}$ is the only brain structure innervated by both tdc2-GAL4 and APL neurons. Four types of tdc2-GAL4 OA neurons (namely, VPM-3, VPM-4, VPM-5, and VUMa2) project to the calyx where the MB receives olfactory input and the $\gamma$ lobes comprising MB axons (Busch et al., 2009), whereas the APL neurons innervate all MB structures where they are both presynaptic and postsynaptic (Liu and Davis, 2009; Wu et al., 2013). The APL neurons use both OA and GABA as neurotransmitters and engage in a feedback loop wherein the $\mathrm{MB}$ 
activates the APL and the APL inhibits the $\mathrm{MB}$, thereby controlling odor discrimination (Liu and Davis, 2009; Wu et al., 2013; Lin et al., 2014). This feedback loop is modulated by DA, which suppresses the APL through $\mathrm{dD} 2 \mathrm{R}$ for $\mathrm{CS}$ processing (Zhou et al., 2019). It is tempting to speculate that the APL uses $\mathrm{OA}$ output for CS processing through $\operatorname{Oct} \beta 1 \mathrm{R}$ in the $\alpha \beta$ neurons. The tdc2GAL4-positive OA neurons mediating olfactory conditioning have not been identified in Drosophila; however, in the honeybee, the OA-VUMmx1 neuron projecting to the calyx and the antennal lobe processes appetitive US (Hammer, 1993). The fly homolog of VUMmx1 is the OA-VUMa2 neuron that is positive for tdc2-GAL4 (Busch et al., 2009), serving as a likely candidate to process appetitive US. There is no information on the OA-VPM neurons or their homologs in other insects; nonetheless, their projection onto the MB calyx and lobes makes them potential candidates to process aversive US. This predicts that discrete OA neurons take part in the CS and US pathways for aversive learning, and this notion is consistent with the finding by Boto et al. (2019) that two distinct types of DA neurons independently regulate the CS and US pathways.

The modes of the $\mathrm{OA}$ and GABA transmissions of the APL (i.e., whether they are released together or independently and whether they act on the same or different postsynaptic sites) are unknown. It is thus difficult to assign the effects of synaptic activity manipulations (e.g., blockade via $\mathrm{Shi}^{\mathrm{ts}}$ and activation via TrpA1) to OA or GABA actions. However, the Gad and Rdl RNAi studies indicate that selective suppression of the APL GABA output or the GABA input to the $\mathrm{MB}$ enhances aversive learning (Liu et al., 2009; Liu and Davis, 2009), which is contrary to our finding that selective suppression of the APL OA output or the OA input to the $\mathrm{MB}$ through $\operatorname{Oct} \beta 1 \mathrm{R}$ impairs aversive learning. The opposite actions of $\mathrm{OA}$ and GABA released from the APL onto the $\mathrm{MB}$ implicate that their release dynamics or functional sites may be distinct. In addition to aversive learning, the APL OA signal modulates amnesia-resistant memory (ARM) consolidation and expression through $\operatorname{Oct} \beta 2 \mathrm{R}$ in the $\mathrm{MB}$ $\alpha^{\prime} \beta^{\prime}$ neurons (Wu et al., 2013; Yang et al., 2016). We found normal $3 \mathrm{~h}$ memory of oct $\beta 2 r$ but impaired $3 \mathrm{~h}$ memory of oct $\beta$ 1r mutants, which are different from the findings (normal $3 \mathrm{~h} \mathrm{ARM} \mathrm{of} \mathrm{oct} \beta \mathrm{lr}$ and impaired $3 \mathrm{~h}$ ARM of oct $\beta 2 r$
A
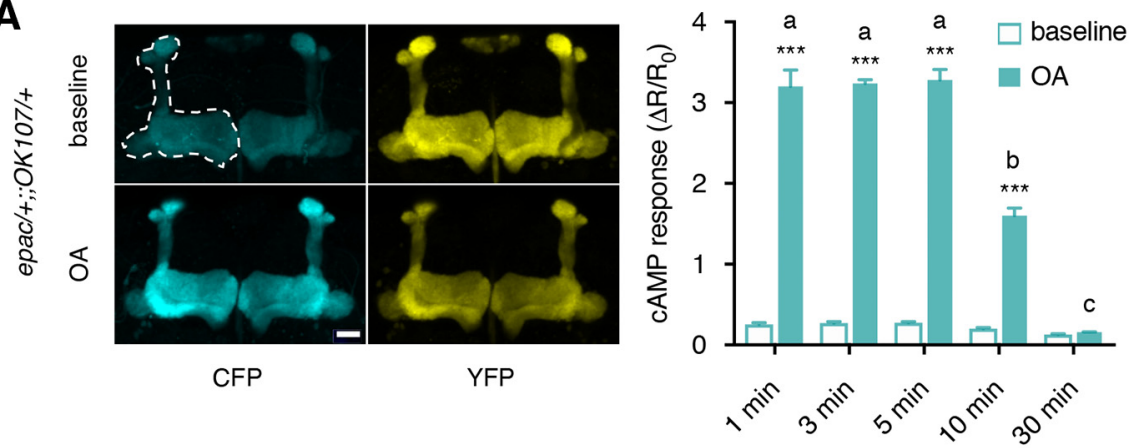

B

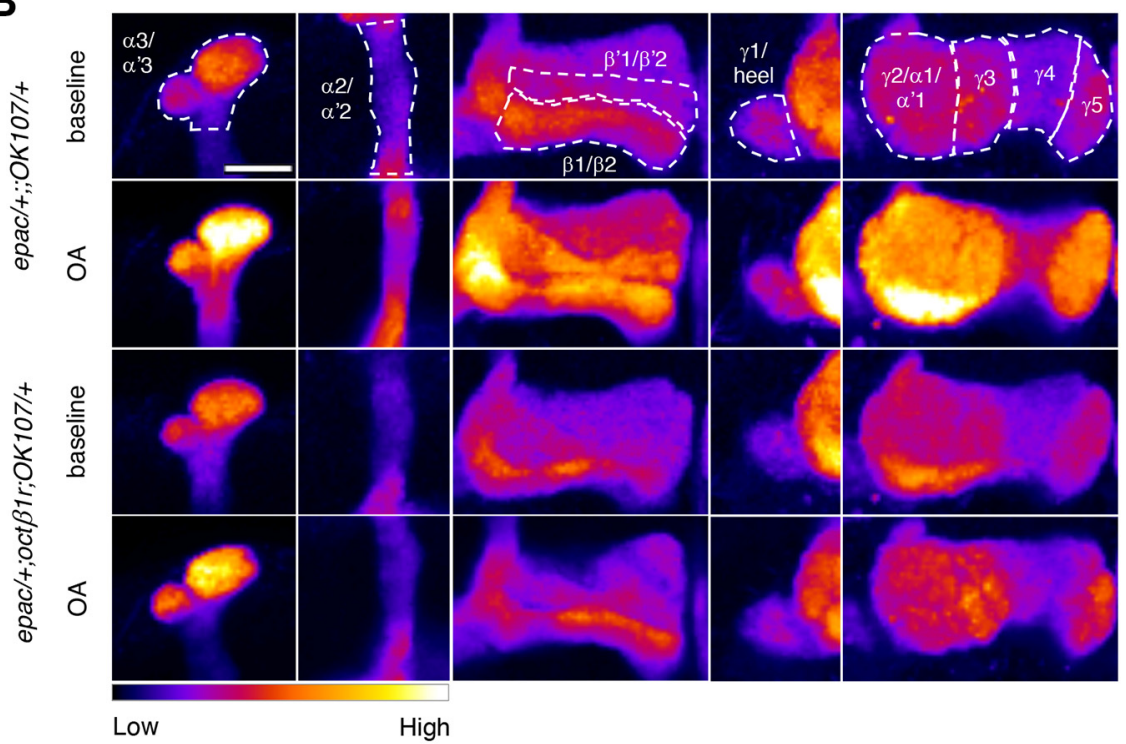

C

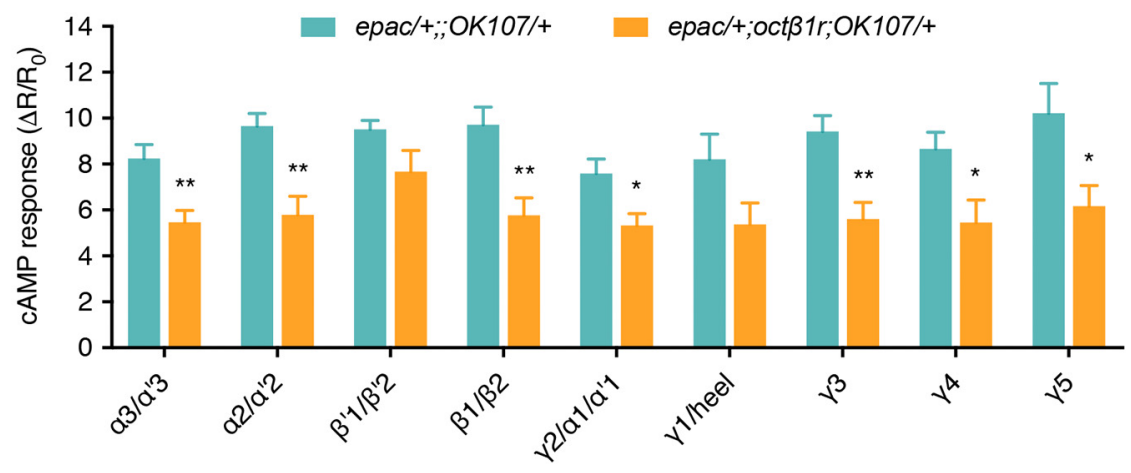

Figure 4. The oct $\beta 1 \mathrm{r}$ mutant have the dampened cAMP response in the MB on OA treatment. $A$, Left, Representative confocal images of CFP and YFP emission in the MB lobes of the control (UAS-Epac1-camps/+;; OK107/+) brains at 3 min after HL3 (vehicle; baseline) or OA treatment. The MB lobes are outlined by broken white lines. Right, The CAMP response was measured at various time points after vehicle (baseline) or OA treatment in the MB lobes of the control (UAS-Epac1-camps $/+; 0$ OK107/+) brains ( $\left.{ }^{* * *} p<0.0001, n=4-6\right)$. The letter codes (" $a$," "b," and " $c$ ") denote significant differences $(p<0.0001)$ among the OA-induced cAMP responses at different time points. Scale bar, $25 \mu \mathrm{m}$. B, Representative confocal images depicting the cAMP level (represented by (FP emission shown in a fire scale) between baseline and $O A$ treatment in the brains of the control (UAS-Epac1-camps/+;;0K107/+) or oct $\beta 1$ r mutant (UAS-Epac1-camps/+; oct $\beta 1 r ; 0 K 107 /+$ ). OA treatment drastically increased cAMP levels (elevated (FP signal) in the control but not in the oct $\beta 1 \mathrm{r} \mathrm{MB}$. Shown are subregions $\left(\alpha 3 / \alpha^{\prime} 3 ; \alpha 2 / \alpha^{\prime} 2 ; \beta 1-2\right.$ and $\beta^{\prime} 1-2 ; \gamma 1 /$ heel; $\gamma 2 / \alpha 1 / \alpha^{\prime} 1$ and $\left.\gamma 3-5\right)$ of the MB lobes that are delineated by broken white lines. The images and quantifications were performed on the brains at 3 min after vehicle or $0 \mathrm{~A}$ treatments. Scale bar, $25 \mu \mathrm{m}$. C, Quantification of the peak CAMP response revealed that all subregions except for the $\beta^{\prime} 1-2$ and $\gamma 1 /$ heel in the oct $\beta 1 r$ MB had significantly dampened responses to $0 \mathrm{~A}$ $\left({ }^{*} p<0.05,{ }^{* *} p<0.01, n=10\right)$. 
A

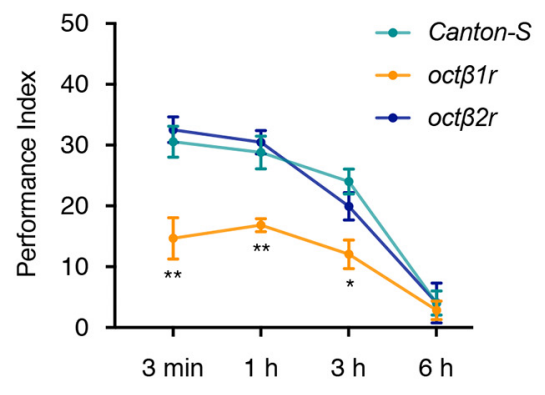

\section{C}

$$
\text { Low }
$$
High
B

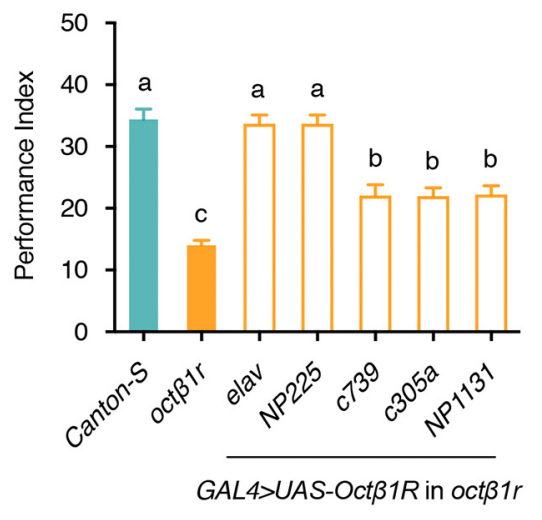

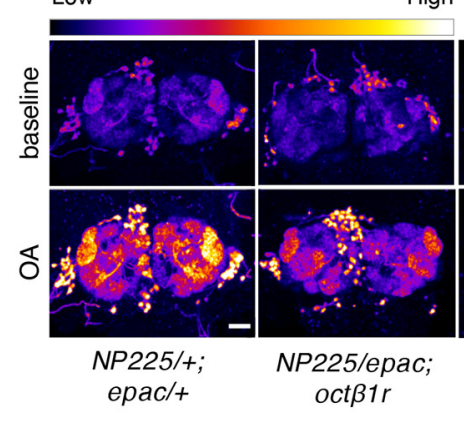

PN dendrites

D

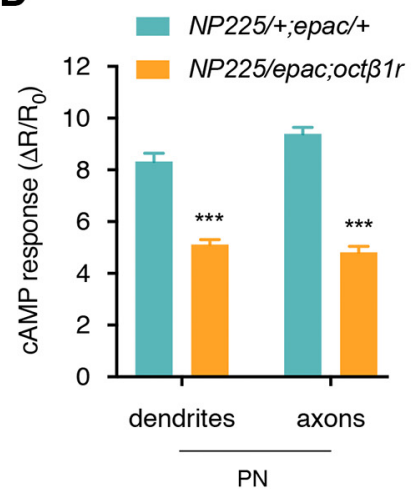

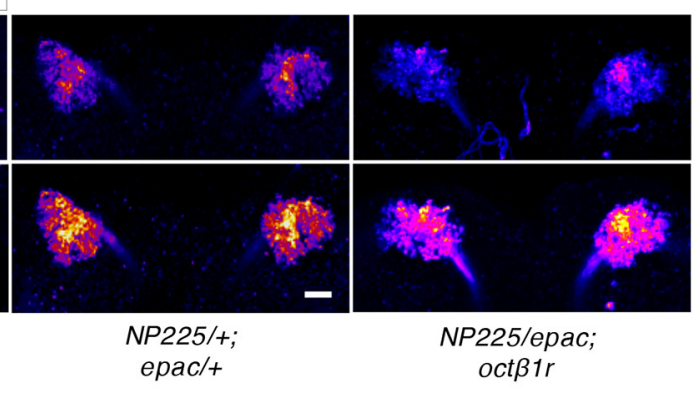

PN axons

E

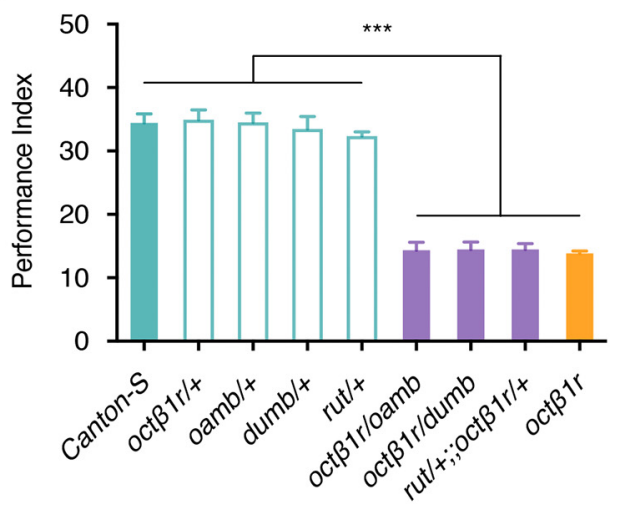

Figure 5. The action of $0 \mathrm{ct} \beta 1 \mathrm{R}$ in the PN fully supports appetitive learning. $A$, oct $\beta 1 \mathrm{r}$ mutants showed defective performance immediately $(3 \mathrm{~min}), 1 \mathrm{~h}$, and $3 \mathrm{~h}$, but not $6 \mathrm{~h}$, after training in appetitive olfactory conditioning $\left({ }^{*} p<0.05,{ }^{* *} p<0.001\right.$, $n=6$ ). $\boldsymbol{B}$, Restored $0 \mathrm{ct} \beta 1 \mathrm{R}$ (via UAS-Oct $\beta 1 R$ ) expression in either all neurons (elav-GAL4) or the PN (NP225-GAL4) fully rescued the learning phenotype of oct $\beta \operatorname{lr}$ (the letter code "a"; $p>0.05, n=12$ ). However, the oct $\beta 1 r$ flies with $0 \mathrm{ct} \beta 1 \mathrm{R}$ re-expression in individual MB subsets ( $\gamma$, NP1131-GAL4; $\alpha \beta$, C739-GAL4; $\alpha^{\prime} \beta^{\prime}$, C305a-GAL4) showed marginal yet significant improvement in olfactory learning (the letter codes " $c$ " and " $\mathrm{b}$ "; $p<0.05, n=12$ ). C, Representative confocal images showing the cAMP levels in the PN dendrites and axons of the baseline versus OA-treated control (NP225-GAL4/+;UAS-Epac1-camps/+) and oct $\beta$ 1r mutant (NP225GAL4/UAS-Epac1-camps;oct $\beta$ 1r). OA treatment increased CAMP levels (elevated (FP signal) in both PN dendrites and axons to a lesser extent in the oct $\beta 1 \mathrm{r}$ mutant compared with the control. Scale bar, $25 \mu \mathrm{m}$. D, Quantified peak cAMP responses. The PN dendrites and axons of octB1r had significantly dampened responses to $\left.O A{ }^{* * *} p<0.0001 ; n=12\right)$. $\boldsymbol{E}$, The flies with the transheterozygous

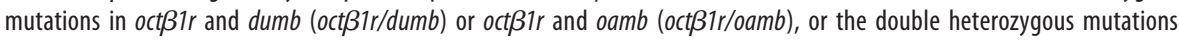
in oct $\beta 1 \mathrm{r}$ and rut (rut/+, $0 \mathrm{oct} \beta 1 \mathrm{r} /+)$ showed impaired appetitive learning compared with Canton-S or the heterozygotes

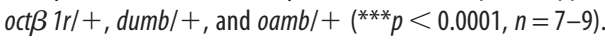

mutants) of the Wu et al. (2013) study. This could be due to several differences that include CS odorants, the nature and genetic backgrounds of oct $\beta 1 r$ and oct $\beta 2 r$ mutants (RNAi-mediated knockdown causing $40-60 \%$ reduction in mRNA levels in the study by Wu et al., 2013), and the methods to measure $3 \mathrm{~h}$ memory (ARM measured after cold shock). The follow-up studies incorporating these factors would clarify the differences in $3 \mathrm{~h}$ memory. Together, the APL OA signals promote aversive olfactory learning and ARM memory through separate $\beta$ like receptors located in the distinct MB subsets, namely $\operatorname{Oct} \beta 1 \mathrm{R}$ in $\alpha \beta$ and $\operatorname{Oct} \beta 2 \mathrm{R}$ in $\alpha^{\prime} \beta^{\prime}$, respectively.

$\mathrm{OA}$ increases cAMP in all MB and PN dendritic and axonal structures (Tomchik and Davis, 2009), which we confirmed in this study. We further demonstrate that the OA-induced increase in cAMP is mediated by $\operatorname{Oct} \beta 1 \mathrm{R}$ in all $\mathrm{MB}$ and $\mathrm{PN}$, which is the first to clarify $\operatorname{Oct} \beta 1 \mathrm{R}$ as an upstream signal for the cAMP increase and the first to substantiate the in vitro analysis on Oct $\beta 1 \mathrm{R}$ (Maqueira et al., 2005) ex vivo. Similar to OA, DA activates the increase in cAMP in all MB structures (Tomchik and Davis, 2009). Notably, both $\operatorname{Oct} \beta 1 \mathrm{R}$ and $\mathrm{dDA} 1$ are present in all MB neurons (Kim et al., 2003; Shih et al., 2019), yet their activities only in the $\alpha \beta$ and $\gamma$ neurons, respectively, are required for aversive learning (this study; Kim et al., 2007a; Qin et al., 2012). This could be due to selective OA/DA input that exclusively activates $\alpha \beta$-Oct $\beta 1 \mathrm{R} /$ $\gamma$-dDA1 or selective activity of the MB output neurons (MBONs) in $\alpha \beta / \gamma$ (Aso et al., 2014a) that convey the Oct $\beta 1 \mathrm{R} / \mathrm{dDA} 1$ information. Together, our study indicates that aversive learning is processed by two parallel circuits consisting of the well characterized DA (PPL1 $\gamma 1$ pedc)-dDA1 (MB- $\gamma$ )-MBON (MBON- $\gamma 1$ pedc $>\alpha / \beta$, MBON- $\gamma 5 \beta^{\prime}$ $2 \mathrm{a} \beta^{\prime} 2 \mathrm{mp}$; Aso et al., 2014b; Owald et al., 2015; Yamazaki et al., 2018), and the OA-Oct $\beta 1 \mathrm{R} \quad(\mathrm{MB}-\alpha \beta)$-MBON $\quad$ (this study) pathways (Fig. 6). The MBONs with dendrites in $\alpha \beta$ (7 MBON types of a total of 22; Aso et al., 2014b) are good candidates to process the OA-Oct $\beta 1 \mathrm{R}$ information for aversive learning. Supporting this notion, the MBON$\beta 2 \beta^{\prime} 2 \mathrm{a}$ activity modulates olfactory conditioning (Owald et al., 2015). Alternatively, the MBONs with dendrites in $\alpha \beta$ as well as $\gamma$ may convey both $\operatorname{Oct} \beta 1 \mathrm{R}$ and $\mathrm{dDA} 1$ information for aversive learning. For example, MBON- $\gamma 1$ pedc $>\alpha / \beta$ has dendrites in $\gamma$ lpedc and $\alpha \beta$ s and axons in $\alpha \beta$ lobes, crepine, and superior intermediate protocerebrum, and its activity modulates aversive learning (Perisse et al., 2016), thus serving as a good candidate conveying both $\operatorname{Oct} \beta 1 \mathrm{R}$ and $\mathrm{dDA} 1$ signals for learned avoidance behavior. An anomaly in either Oct $\beta 1 \mathrm{R}$ or $\mathrm{dDA} 1$ signaling to MBON- $\gamma 1$ pedc $>\alpha / \beta$ would lead to poor aversive learning. 


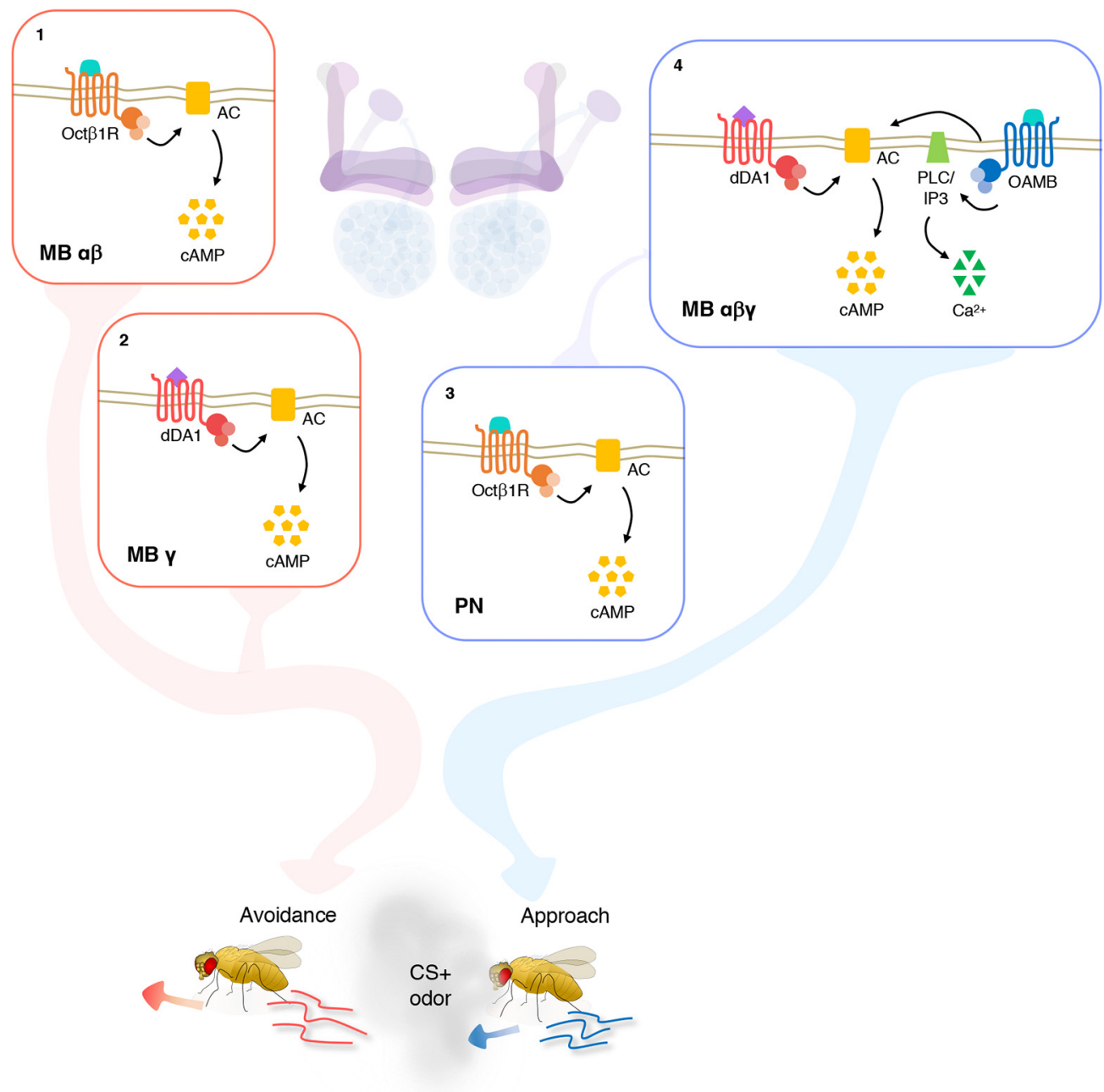

Figure 6. Working model for the pathways that $O A$ and DA process aversive and appetitive olfactory learning. In aversive conditioning, the $O A$ and DA neurons deliver the aversive US information to $0 \mathrm{c}+\beta 1 \mathrm{R}$ in the $\mathrm{MB} \alpha \beta$ and $\mathrm{dDA} 1$ in the $\mathrm{MB} \gamma$, respectively, which, in concert with the $\mathrm{CS}$ input, activate the coincidence detector Rut-AC. The parallel cAMP signaling in the $\alpha \beta$ (1, red box) and $\gamma$ (2, red box) modulates the MB outputs to MBONs promoting avoidance behavior. Abnormal signaling in either OA-0ct $\beta 1 \mathrm{R}$ in $\alpha \beta$ or DA-dDA1 in $\gamma$ leads to defective aversive learning. In appetitive conditioning, the collective activation of $0 \mathrm{~A}-0 \mathrm{ct} \beta 1 \mathrm{R}$ in the PN (3, blue box), which projects to the MB, as well as OA-OAMB and DA-dDA1 in the MB $\alpha \beta \gamma(4$, blue box) recruit both Rut-AC and phospholipase C (PLC) to stimulate the CAMP and $\mathrm{Ca}^{2+}$ signaling, which in turn modulate the MB outputs to the MBONs promoting approach behavior. Thus, the $\mathrm{OA}$ and $\mathrm{DA}$ systems act together for aversive and appetitive learning through distinct neural sites and intracellular signaling.

Rut-AC is a coincidence detector for associative learning and memory (Guven-Ozkan and Davis, 2014). We show that oct $\beta$ 1r and rut are genetically interacting for aversive learning. The previous findings on the functional site of Rut-AC are somewhat confusing. Blum et al. (2009) identify $\gamma$ neurons as the site that Rut-AC mediates aversive learning, whereas Zars et al. (2000) and Akalal et al. (2006) demonstrate that Rut-AC in both $\gamma$ and $\alpha \beta$ neurons is important. The major difference is the rut allele: Blum et al. (2009) used rut ${ }^{l}$ but Akalal et al. (2006) and our study used rut $^{2080}$, which displays a more severe learning deficit than $r u t^{1}$. Thus, Rut-AC likely serves as a key downstream effector for both $\operatorname{Oct} \beta 1 \mathrm{R}$ and $\mathrm{dDA} 1$ in $\alpha \beta$ and $\gamma$, respectively. Regarding the downstream effectors of cAMP, Oct $\beta 1 \mathrm{R}$, and $\mathrm{dDA} 1$ seems to involve distinct signaling pathways. Gervasi et al. (2010) demonstrate that $\mathrm{OA}$ activates protein kinase $\mathrm{A}$ (PKA) in $\alpha \beta$ in a Rut-AC-dependent manner but that DA does not induce PKA activation in $\gamma$. In vivo functional imaging, on the contrary, reveals that an elevated cAMP level leads to enhanced calcium responses to CS odors in $\gamma$ but not $\alpha \beta$ (Boto et al., 2014). It is tempting to speculate that the $\gamma$ dDA1-cAMP pathway directly activates cyclic-nucleotide gated ion channels while the $\alpha \beta$
Oct $\beta 1$ R-cAMP pathway recruits PKA to modify ion channel activity or other downstream effectors for aversive learning.

$\mathrm{OA}$ is a major neuromodulator for appetitive learning, and $\alpha 1$-like OAMB in $\alpha \beta \gamma$ is a key receptor conveying the OA signal (Kim et al., 2013). Here, we show that $\operatorname{Oct} \beta 1 \mathrm{R}$ is also important for appetitive learning, and this dual function is similar to dDA1 (Kim et al., 2007a). However, there is a major difference: dDA1 processes both aversive and appetitive learning in $\mathrm{MB} \gamma$, but the functional sites of $\operatorname{Oct} \beta 1 \mathrm{R}$ are distinct (i.e., $\mathrm{MB} \alpha \beta$ for aversive learning and PN for appetitive learning). Thum et al. (2007) demonstrate that Rut-AC restored in either MB or PN fully rescues the phenotype of the rut mutant in appetitive conditioning, suggesting multiple yet redundant neural sites for Rut-AC-dependent learning. It is yet unclear whether $\mathrm{dDA} 1$ recruits RutAC for appetitive memory; however, our study clarifies that the PN Rut-AC is activated by $\operatorname{Oct} \beta 1 \mathrm{R}$ for the acquisition of appetitive memory. Together, OA mediates positively reinforced learning through the following two parallel circuits: the OAOct $\beta 1$ R-Rut-AC pathway in PN and the OA-OAMB-intracellular calcium pathway in $\mathrm{MB} \alpha \beta \gamma$. 


\section{References}

Akalal DB, Wilson CF, Zong L, Tanaka NK, Ito K, Davis RL (2006) Roles for Drosophila mushroom body neurons in olfactory learning and memory. Learn Mem 13:659-668.

Akbari OS, Oliver D, Eyer K, Pai CY (2009) An Entry/Gateway cloning system for general expression of genes with molecular tags in Drosophila melanogaster. BMC Cell Biol 10:8.

Aso Y, Hattori D, Yu Y, Johnston RM, Iyer NA, Ngo TT, Dionne H, Abbott LF, Axel R, Tanimoto H, Rubin GM (2014a) The neuronal architecture of the mushroom body provides a logic for associative learning. Elife 3: e04577.

Aso Y, Sitaraman D, Ichinose T, Kaun KR, Vogt K, Belliart-Guérin G, Plaçais P-Y, Robie AA, Yamagata N, Schnaitmann C, Rowell WJ, Johnston RM, Ngo T-TB, Chen N, Korff W, Nitabach MN, Heberlein U, Preat T, Branson KM, Tanimoto H, et al. (2014b) Mushroom body output neurons encode valence and guide memory-based action selection in Drosophila. Elife 3:e04580.

Beck CD, Schroeder B, Davis RL (2000) Learning performance of normal and mutant Drosophila after repeated conditioning trials with discrete stimuli. J Neurosci 20:2944-2953.

Berry JA, Cervantes-Sandoval I, Nicholas EP, Davis RL (2012) Dopamine is required for learning and forgetting in Drosophila. Neuron 74:530542.

Blum AL, Li W, Cressy M, Dubnau J (2009) Short- and long-term memory in Drosophila require cAMP signaling in distinct neuron types. Curr Biol 19:1341-1350.

Boto T, Louis T, Jindachomthong K, Jalink K, Tomchik SM (2014) Dopaminergic modulation of cAMP drives nonlinear plasticity across the Drosophila mushroom body lobes. Curr Biol 24:822-831.

Boto T, Stahl A, Zhang X, Louis T, Tomchik SM (2019) Independent contributions of discrete dopaminergic circuits to cellular plasticity, memory strength, and valence in Drosophila. Cell Rep 27:2014-2021.e2.

Brand AH, Perrimon N (1993) Targeted gene expression as a means of altering cell fates and generating dominant phenotypes. Development 118 : 401-415.

Brown JB, Boley N, Eisman R, May GE, Stoiber MH, Duff MO, Booth BW, Wen J, Park S, Suzuki AM, Wan KH, Yu C, Zhang D, Carlson JW, Cherbas L, Eads BD, Miller D, Mockaitis K, Roberts J, Davis CA, et al. (2014) Diversity and dynamics of the Drosophila transcriptome. Nature 512:393-399.

Busch S, Selcho M, Ito K, Tanimoto H (2009) A map of octopaminergic neurons in the Drosophila brain. J Comp Neurol 513:643-667.

Chintapalli VR, Wang J, Dow JA (2007) Using FlyAtlas to identify better Drosophila melanogaster models of human disease. Nat Genet 39:715720.

Claridge-Chang A, Roorda RD, Vrontou E, Sjulson L, Li H, Hirsh J, Miesenböck G (2009) Writing memories with light-addressable reinforcement circuitry. Cell 139:405-415.

Cognigni P, Felsenberg J, Waddell S (2018) Do the right thing: neural network mechanisms of memory formation, expression and update in Drosophila. Curr Opin Neurobiol 49:51-58.

Crittenden JR, Skoulakis EM, Han KA, Kalderon D, Davis RL (1998) Tripartite mushroom body architecture revealed by antigenic markers. Learn Mem 5:38-51.

Davie K, Janssens J, Koldere D, De Waegeneer M, Pech U, Kreft E, Aibar S, Makhzami S, Christiaens V, Bravo González-Blas C, Poovathingal S, Hulselmans G, Spanier KI, Moerman T, Vanspauwen B, Geurs S, Voet T, Lammertyn J, Thienpont B, Liu S, et al. (2018) A single-cell transcriptome atlas of the aging Drosophila brain. Cell 174:982-998.e20.

Farooqui T, Robinson K, Vaessin H, Smith BH (2003) Modulation of early olfactory processing by an octopaminergic reinforcement pathway in the honeybee. J Neurosci 23:5370-5380.

FlyBase Consortium (2003) The FlyBase database of the Drosophila genome projects and community literature. Nucleic Acids Res 31:172-175.

Gervasi N, Tchénio P, Preat T (2010) PKA dynamics in a Drosophila learning center: coincidence detection by rutabaga adenylyl cyclase and spatial regulation by dunce phosphodiesterase. Neuron 65:516-529.

Graveley BR, Brooks AN, Carlson JW, Duff MO, Landolin JM, Yang L, Artieri CG, van Baren MJ, Boley N, Booth BW, Brown JB, Cherbas L, Davis CA, Dobin A, Li R, Lin W, Malone JH, Mattiuzzo NR, Miller D, Sturgill D, et al. (2011) The developmental transcriptome of Drosophila melanogaster. Nature 471:473-479.
Guven-Ozkan T, Davis RL (2014) Functional neuroanatomy of Drosophila olfactory memory formation. Learn Mem 21:519-526.

Hammer M (1993) An identified neuron mediates the unconditioned stimulus in associative olfactory learning in honeybees. Nature 366:5963.

Han KA, Millar NS, Davis RL (1998) A novel octopamine receptor with preferential expression in Drosophila mushroom bodies. J Neurosci 18:36503658.

Himmelreich S, Masuho I, Berry JA, MacMullen C, Skamangas NK, Martemyanov KA, Davis RL (2017) Dopamine receptor DAMB signals via Gq to mediate forgetting in Drosophila. Cell Rep 21:2074-2081.

Iliadi KG, Iliadi N, Boulianne GL (2017) Drosophila mutants lacking octopamine exhibit impairment in aversive olfactory associative learning. Eur J Neurosci 46:2080-2087.

Johnson O, Becnel J, Nichols CD (2011) Serotonin receptor activity is necessary for olfactory learning and memory in Drosophila melanogaster. Neuroscience 192:372-381.

Kaczer L, Maldonado H (2009) Contrasting role of octopamine in appetitive and aversive learning in the crab Chasmagnathus. PLoS One 4:e6223.

Kim YC, Lee HG, Seong CS, Han KA (2003) Expression of a D1 dopamine receptor $\mathrm{dDA} 1 / \mathrm{DmDOP} 1$ in the central nervous system of Drosophila melanogaster. Gene Expr Patterns 3:237-245.

Kim YC, Lee HG, Han KA (2007a) D1 dopamine receptor dDA1 is required in the mushroom body neurons for aversive and appetitive learning in Drosophila. J Neurosci 27:7640-7647.

Kim YC, Lee HG, Han KA (2007b) Classical reward conditioning in Drosophila melanogaster. Genes Brain Behav 6:201-207.

Kim YC, Lee HG, Lim J, Han KA (2013) Appetitive learning requires the alpha1-like octopamine receptor OAMB in the Drosophila mushroom body neurons. J Neurosci 33:1672-1677.

Lee HG, Seong CS, Kim YC, Davis RL, Han KA (2003) Octopamine receptor OAMB is required for ovulation in Drosophila melanogaster. Dev Biol 264:179-190.

Li H, Horns F, Wu B, Xie Q, Li J, Li T, Luginbuhl DJ, Quake SR, Luo L (2017) Classifying Drosophila olfactory projection neuron subtypes by single-cell RNA sequencing. Cell 171:1206-1220.e22.

Lim J, Sabandal PR, Fernandez A, Sabandal JM, Lee HG, Evans P, Han KA (2014) The octopamine receptor Oct $\beta 2 \mathrm{R}$ regulates ovulation in Drosophila melanogaster. PLoS One 9:e104441.

Lin S, Owald D, Chandra V, Talbot C, Huetteroth W, Waddell S (2014) Neural correlates of water reward in thirsty Drosophila. Nat Neurosci 17:1536-1542.

Liu C, Plaçais PY, Yamagata N, Pfeiffer BD, Aso Y, Friedrich AB, Siwanowicz I, Rubin GM, Preat T, Tanimoto H (2012) A subset of dopamine neurons signals reward for odour memory in Drosophila. Nature 488:512-516.

Liu X, Davis RL (2009) The GABAergic anterior paired lateral neuron suppresses and is suppressed by olfactory learning. Nat Neurosci 12: 53-59.

Liu X, Buchanan ME, Han KA, Davis RL (2009) The GABA receptor RDL suppresses the conditioned stimulus pathway for olfactory learning. J Neurosci 29:1573-1579.

Maqueira B, Chatwin H, Evans PD (2005) Identification and characterization of a novel family of Drosophila beta-adrenergic-like octopamine G-protein coupled receptors. J Neurochem 94:547-560.

McGuire SE, Le PT, Osborn AJ, Matsumoto K, Davis RL (2003) Spatiotemporal rescue of memory dysfunction in Drosophila. Science 302:1765-1768.

Mizunami M, Matsumoto Y (2017) Roles of octopamine and dopamine neurons for mediating appetitive and aversive signals in pavlovian conditioning in crickets. Front Physiol 8:1027.

Nikolaev VO, Bünemann M, Hein L, Hannawacker A, Lohse MJ (2004) Novel single chain cAMP sensors for receptor-induced signal propagation. J Biol Chem 279:37215-37218.

Owald D, Felsenberg J, Talbot CB, Das G, Perisse E, Huetteroth W, Waddell S (2015) Activity of defined mushroom body output neurons underlies learned olfactory behavior in Drosophila. Neuron 86:417-427.

Perisse E, Owald D, Barnstedt O, Talbot CB, Huetteroth W, Waddell S (2016) Aversive learning and appetitive motivation toggle feed-forward inhibition in the Drosophila mushroom body. Neuron 90:1086-1099.

Pfeiffer BD, Jenett A, Hammonds AS, Ngo TT, Misra S, Murphy C, Scully A, Carlson JW, Wan KH, Laverty TR, Mungall C, Svirskas R, Kadonaga JT, Doe CQ, Eisen MB, Celniker SE, Rubin GM (2008) Tools for 
neuroanatomy and neurogenetics in Drosophila. Proc Natl Acad Sci U S A 105:9715-9720.

Qin H, Cressy M, Li W, Coravos JS, Izzi SA, Dubnau J (2012) Gamma neurons mediate dopaminergic input during aversive olfactory memory formation in Drosophila. Curr Biol 22:608-614.

Schwaerzel M, Monastirioti M, Scholz H, Friggi-Grelin F, Birman S, Heisenberg M (2003) Dopamine and octopamine differentiate between aversive and appetitive olfactory memories in Drosophila. J Neurosci 23:10495-10502.

Shafer OT, Kim DJ, Dunbar-Yaffe R, Nikolaev VO, Lohse MJ, Taghert PH (2008) Widespread receptivity to neuropeptide PDF throughout the neuronal circadian clock network of Drosophila revealed by real-time cyclic AMP imaging. Neuron 58:223-237.

Shih MM, Davis FP, Henry GL, Dubnau J (2019) Nuclear transcriptomes of the seven neuronal cell types that constitute the Drosophila mushroom bodies. G3 (Bethesda) 9:81-94.

Sitaraman D, LaFerriere H, Birman S, Zars T (2012) Serotonin is critical for rewarded olfactory short-term memory in Drosophila. J Neurogenet 26:238-244.

Thibault ST, Singer MA, Miyazaki WY, Milash B, Dompe NA, Singh CM, Buchholz R, Demsky M, Fawcett R, Francis-Lang HL, Ryner L, Cheung LM, Chong A, Erickson C, Fisher WW, Greer K, Hartouni SR, Howie E, Jakkula L, Joo D, et al. (2004) A complementary transposon tool kit for Drosophila melanogaster using $\mathrm{P}$ and piggyBac. Nat Genet 36:283-287.
Thum AS, Jenett A, Ito K, Heisenberg M, Tanimoto H (2007) Multiple memory traces for olfactory reward learning in Drosophila. J Neurosci 27:11132-11138.

Tomchik SM, Davis RL (2009) Dynamics of learning-related cAMP signaling and stimulus integration in the Drosophila olfactory pathway. Neuron 64:510-521.

Wu CL, Shih MF, Lee PT, Chiang AS (2013) An octopamine-mushroom body circuit modulates the formation of anesthesia-resistant memory in Drosophila. Curr Biol 23:2346-2354.

Yamazaki D, Hiroi M, Abe T, Shimizu K, Minami-Ohtsubo M, Maeyama Y, Horiuchi J, Tabata T (2018) Two parallel pathways assign opposing odor valences during Drosophila memory formation. Cell Rep 22:2346-2358.

Yang CH, Shih MF, Chang CC, Chiang MH, Shih HW, Tsai YL, Chiang AS, Fu TF, Wu CL (2016) Additive expression of consolidated memory through Drosophila mushroom body subsets. PLoS Genet 12:e1006061.

Zars T, Fischer M, Schulz R, Heisenberg M (2000) Localization of a shortterm memory in Drosophila. Science 288:672-675.

Zhou C, Huang H, Kim SM, Lin H, Meng X, Han KA, Chiang AS, Wang JW, Jiao R, Rao Y (2012) Molecular genetic analysis of sexual rejection: roles of octopamine and its receptor OAMB in Drosophila courtship conditioning. J Neurosci 32:14281-14287.

Zhou M, Chen N, Tian J, Zeng J, Zhang Y, Zhang X, Guo J, Sun J, Li Y, Guo A, Li Y (2019) Suppression of GABAergic neurons through D2-like receptor secures efficient conditioning in Drosophila aversive olfactory learning. Proc Natl Acad Sci U S A 116:5118-5125. 